\title{
Clinical characteristics and poor predictors of anti-NXP2 antibody-associated Chinese JDM children
}

\author{
Xinning Wang ${ }^{\dagger}$, Yuchuan Ding ${ }^{\dagger}$, Zhixuan Zhou ${ }^{* \dagger}$, Jun Hou, Yingjie Xu and Jianguo Li $^{* \dagger}$ (B)
}

\begin{abstract}
Background: Juvenile dermatomyositis (JDM) is a rare and sometimes fatal disease in children. The anti-NXP2 antibody is one of the most common antibodies and muscle ischaemia associated with NXP2 autoantibodies was a severe subtype of JDM. Further information is needed regarding clinical characteristics and factors associated with poor prognosis. But there are no reports about clinical characteristics and high risk factor of poor prognosis. For the first time, we introduced the clinical characteristics and poor predictors of anti-NXP2 antibody-associated juvenile dermatomyositis in Chinese children.
\end{abstract}

Methods: Twenty-six patients with anti-NXP2 antibody-related JDM from 85 JDM Chinese patients were diagnosed from January 2016 to November 2019. Logistic regression was used to analyze the risk factors for refractory cases and mortality.

Results: The ratio of male to female was 1:1.9. The median age of onset was 4.5 (1-13) years. Twenty-four cases (92.3\%) had rash and muscle weakness. Treatments included glucocorticoids, immunosuppressive agents, biological agents (7 cases), plasma exchange, Janus kinase inhibitor (7 cases) and autologous stem cell transplant (1 case). Refractory JDM patients (11/26, 42.3\%) were associated with edema, skin ulcer, muscle strength $<=$ grade 3, CD4/CD8 ratio $<1.4$ and ferritin $>200 \mu \mathrm{g} / \mathrm{ml}$. Among 6 cases $(6 / 26,23.1 \%)$ with severe gastrointestinal involvement, 5 cases died and 1 case survived after autologous stem cell transplant (ASCT). The risk factors for gastrointestinal involvement and mortality were edema, skin ulcer, severe muscle weakness (dysphagia/ hoarseness/ soft voice), $\mathrm{BMI}<15$ and ANA positive.

Conclusions: Edema, skin ulcer and severe muscle weakness predicted refractory disease, Gl involvement, and mortality in anti-NXP2 antibody-positive JDM of Chinese children. Decreased CD4/CD8 ratio and high ferritin related with refractory cases, and very low BMI and ANA (+) are probably, associated with gastrointestinal involvement and mortality.

Trial registration: http://www.chictr.org.cn/showproj.aspx?proj=49846.

Keywords: Juvenile dermatomyositis, Anti-nuclear matrix protein 2, Chinese

\footnotetext{
*Correspondence: zhouzhixuan9@sina.com; jianguo_li6@hotmail.com

${ }^{\dagger}$ Zhou Zhixuan and Li Jianguo contributed equally as co-corresponding authors.

'Wang Xinning and Ding Yuchuan contributed equally as co-first authors. Department of Rheumatology and Immunology, The Affiliated Children's Hospital, Capital Institute of Pediatrics, 2 Yabao Road, Chaoyang District, Beijing 100020, China
}

C C The Author(s). 2021 Open Access This article is licensed under a Creative Commons Attribution 4.0 International License, which permits use, sharing, adaptation, distribution and reproduction in any medium or format, as long as you give appropriate credit to the original author(s) and the source, provide a link to the Creative Commons licence, and indicate if changes were made. The images or other third party material in this article are included in the article's Creative Commons licence, unless indicated otherwise in a credit line to the material. If material is not included in the article's Creative Commons licence and your intended use is not permitted by statutory regulation or exceeds the permitted use, you will need to obtain permission directly from the copyright holder. To view a copy of this licence, visit http://creativecommons.org/licenses/by/4.0/. The Creative Commons Public Domain Dedication waiver (http://creativecommons.org/publicdomain/zero/1.0/) applies to the data made available in this article, unless otherwise stated in a credit line to the data. 


\section{Background}

Juvenile dermatomyositis (JDM) is a pediatric-onset idiopathic inflammatory myopathy associated with autoimmune vasculopathy, mainly characterized by proximal muscle weakness and typical rash [1]. The incidence rate is $(2 \sim 4 / 100,0000)$ [2]. China has a huge population of children, while there are few reports on the incidence and clinical features of JDM in Chinese children.

JDM is a highly heterogeneous disease, involving not only muscles and skin, but also other organs including cardiovascular, respiratory, and gastrointestinal systems and even cause considerable mortality [3]. In recent years, myositis-specific autoantibodies (MSAs) were found to be closely associated with distinct clinical features and prognosis of the DM sub-types. It is reported that anti-NXP2 antibody, might be one of the most common MSA groups in JDM which has been reported to have poor outcomes $[4,5]$. Some case reports suggested that gastrointestinal involvement was a serious complication in anti-NXP2 antibody-related JDM $[5,6]$.

Further information is needed regarding features associated with refractory cases and risk factors for death of anti-NXP2 antibody-positive JDM. We present retrospective analysis of features, treatment and outcomes of anti-NXP2 antibody-related Chinese JDM cases.

\section{Patients and methods}

\section{Patients}

Chinese children diagnosed with anti-NXP2 autoantibody positive JDM at Capital Institute of Pediatrics (CIP) from January 2016 to November 2019 were included. Specifically, the inclusion criteria were: 1) age $<18$ years old; 2) diagnosed as JDM based on the Bohan and Peter criteria for myositis [4]; 3) antiNXP2 antibody positive. The exclusion criteria were 1): other diseases that cause weakness or rash (clear alternative diagnosis), or 2) unwillingness to enroll in the study. The age of disease onset was defined as the earliest age that the typical symptoms of JDM appeared. Duration before diagnosis indicates the time from onset to diagnosis. Refractory was defined as the ineffectiveness of glucocorticoids combined with more than two immunosuppressive agents, and (or) need more aggressive treatment like biological agents. Very low BMI was defined as $\mathrm{BMI}<13$. The first-line treatment is Glucocorticoid (GC) combining immunosuppressant. If the response to the treatment is not ideal, another immunosuppressant or biological agents will be added. In the study, all cases were initially treated with GC and immunosuppressive agents except one girl for her parents refused to use GC. This study was approved by Ethics Committee of CIP (KSSHER LL2017068).

\section{Laboratory examinations}

We used immune dot blot to determine the presence of anti-NXP2 antibody in human serum (D-TEK, Belgium). Creatine kinase (CK) were tested by automated biochemical analyzer (Siemens, Germany). Ferritin was measured by quantitative chemiluminescence assay (Abbott Laboratories, US). Anti-nuclear antibodies (ANA) and anti-Ro-52 antibodies were measured by immunofluorescence assay (Euroimmun, US) and immunoblotting (Euroimmun, US) respectively. We assessed CD4/ CD8 ratio by flow cytometry and immunofluorescence (Becton, Dickinson and Company, US).

\section{Statistical analyses}

Characteristics of patients were compared with four kinds of outcomes. Indicators include age at onset, duration, BMI, muscle strength, childhood myositis assessment score (CMAS), CK, ferritin and CD4/CD8 ratio. Continuous variables are expressed as median and range (minimum-maximum) and categorical variables were expressed as frequency and percentage. Associations between the risk factors for poor outcomes were evaluated by univariate logistic regression analysis. Adjusted odds ratio (OR) and 95\% confidence interval (95\% CI) were calculated. In addition, follow-up time was compared using Wilcoxon's signed rank test and each variable was evaluated by Spearman correlation test. $P$ values $<0.05$ (two-sided) were considered as statistically significant. All statistical analyses were performed with $\mathrm{R}$ 3.2.3 (http://www.r-project.org/).

\section{Results}

Patients

Of 85 patients with JDM, 26 were anti-NXP2 autoantibody positive. Among the 26 patients, 13 cases including 4 severe patients were transferred from other hospitals. Ages at onset of these patients ranged from 1 to 13 years with the median age of 4.5 years. Nine cases were found CMAS $<=2$. Baseline characteristics of patients are shown in Table 1. The demographic and clinical characteristics of the patients are presented in Table 2.

\section{Clinical assessment}

Initial CK was recorded in 22 patients (the results of 4 cases transferred from other hospitals were not available. Two cases $(2 / 22,9.1 \%)$ were within normal limits, twelve cases $(12 / 22,54.5 \%)$ were $>1-10 x$ upper limit of normal (ULN) and eight cases were $>10 x$ ULN. ANA and anti-Ro-52 antibody status are shown in Table 2. All of the positive ANA titers were 1:100. Results of imaging examinations including Magnetic resonance imaging (MRI) and High-resolution CT (HRCT) were also showed in Table 2. Pulmonary function was characterized by mild obstructive ventilation dysfunction, 


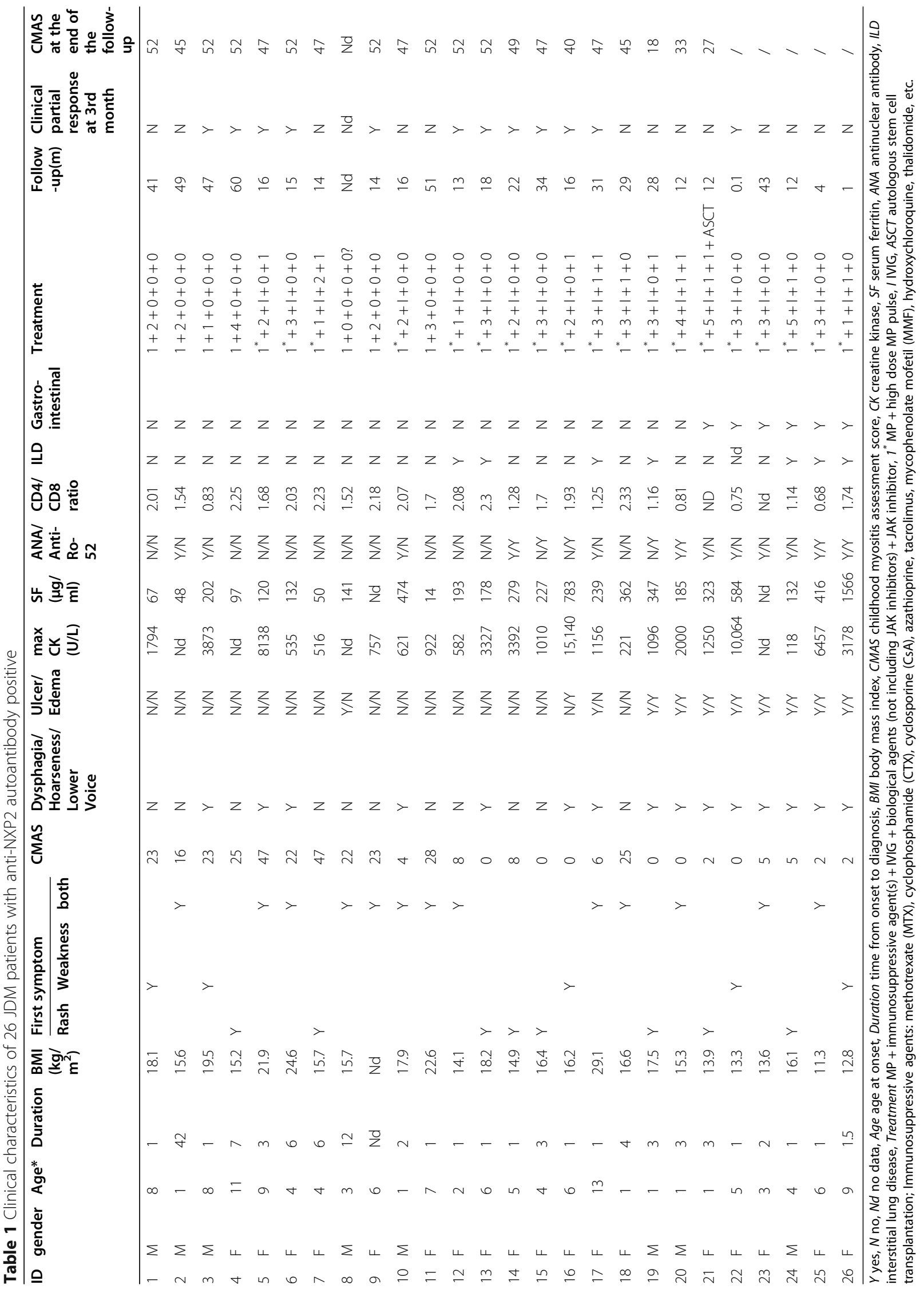


Table 2 Demographic and clinical data of 26 patients with antiNXP2 autoantibody positive JDM

\begin{tabular}{|c|c|}
\hline Baseline characteristics & n (\%) or Median (range) \\
\hline \multicolumn{2}{|l|}{ Diagnosis } \\
\hline$J \mathrm{DM}$ & $26(100 \%)$ \\
\hline \multicolumn{2}{|l|}{ Gender } \\
\hline Male & $9(34.6 \%)$ \\
\hline Female & $17(65.4 \%)$ \\
\hline Age at onset (y) & $4.5(1-13)$ \\
\hline Duration from onset to diagnosis $(\mathrm{m})$ & $2.0(1.0-42.0)$ \\
\hline \multicolumn{2}{|l|}{ First symptom } \\
\hline Rash & $8(30.8 \%)$ \\
\hline Muscle weakness & $5(19.2 \%)$ \\
\hline Rash \& muscle weakness & $13(50 \%)$ \\
\hline \multicolumn{2}{|l|}{ Proximal muscle strength } \\
\hline$<=$ grade 3 & 18(69.2\%) \\
\hline$>$ grade 3 & $8(30.8 \%)$ \\
\hline CMAS & $7(0-47)$ \\
\hline dysphagia/hoarseness/soft voice & $15(57.7 \%)$ \\
\hline \multicolumn{2}{|l|}{ Other signs } \\
\hline Cutaneous ulceration & $10(38.5 \%)$ \\
\hline Periorbital edema & $5(19.2 \%)$ \\
\hline Calcification & $3(11.5 \%)$ \\
\hline \multicolumn{2}{|l|}{ Other organ systems } \\
\hline Arthritis & $8(30.8 \%)$ \\
\hline Interstitial lung disease & $7(26.9 \%)$ \\
\hline Gastrointestinal involvement & $6(23.1 \%)$ \\
\hline \multicolumn{2}{|l|}{ Laboratory testing } \\
\hline $\mathrm{CK}(\mathrm{ng} / \mathrm{ml})$ & $1203(118-15,140)$ \\
\hline Serum ferritin $(\mathrm{ng} / \mathrm{ml})$ & 198(14-1566) \\
\hline ANA (+) only & $8(30.8 \%)$ \\
\hline Anti-Ro52 antibody (+) only & $3(11.5 \%)$ \\
\hline ANA (+) \& Anti-Ro52 antibody (+) & $4(15.4 \%)$ \\
\hline \multicolumn{2}{|l|}{ Other examination } \\
\hline MRI: myositis & 26 \\
\hline EMG: myogenic damage & 18(81.8\%) \\
\hline HRCT: interstitial lung disease & $7(28 \%)$ \\
\hline \multicolumn{2}{|l|}{ Treatment $^{\mathrm{a}}$} \\
\hline$G C+\mid A^{\leq 2} \pm(I V I G)$ & $8(30.8 \%)$ \\
\hline$G C+\mid A^{>2} \pm(I V \mid G)$ & $8(30.8 \%)$ \\
\hline$G C+I A^{\leq 2}+I V I G+B A$ & $4(15.4 \%)$ \\
\hline$G C+I A^{>2}+I V I G+B A$ & $6(23.1 \%)$ \\
\hline Follow-up(m) & $27.5(1.0-106.0)$ \\
\hline Refractory JDM & $11(42.3 \%)$ \\
\hline Death & $5(19.2 \%)$ \\
\hline
\end{tabular}

JDM juvenile dermatomyositis, JPM juvenile polymyositis, CMAS childhood myositis assessment score, $C K$ creatine kinase, normal range: 50-220 U/L; serum ferritin normal range: $15-200 \mathrm{ng} / \mathrm{ml}$, ANA antinuclear antibody, MRI magnetic resonance imaging, EMG electromyography, $H R C T$ high-resolution computed tomography

${ }^{a} \mathrm{GC}$ : glucocorticoids including methylprednisolone and prednisolone; IA: immunosuppressive agents; $\mathrm{IA}^{\leq 2}$ : two or less than 2 types of

immunosuppressive agents; $\mid \mathrm{A}^{>2}$ : more than 2 types of immunosuppressive agents; IVIG: intravenous immunoglobulin; BA: biological agents, including monoclonal antibodies and JAK inhibitors like tofacitinib. m: months for follow-up.

decreased small airway function, and 3 cases had mildly increased residual volume.

\section{Treatment and prognosis}

Treatment started promptly upon diagnosis. Regimens were showed in Table 1. (GC) was the first-line therapy, except one case started with biological agent because parents refused to use GC. If GC plus two immunosuppressive agents failed, more immunosuppressive agents or/and biological agents were be given. One case received autologous stem cell transplantation (ASCT) for severity and poor response to medicine. Tofacitinib (Janus-kinase inhibitors, JAKi) or Ruxolitinib was used in 7 cases. Two were treated with JAKi due to intractable rash at 4 months and 1 year respectively; four were treated with JAKi because of the aggressive nature of the disease or no remission with GC and immunosuppressive agents; and one was treated with JAKi after ASCT for refractory rash. Twenty-five patients were followed up for 27.5 (1.0-106.0) months (one case was lost for follow-up). Twenty patients improved and five died of gastrointestinal perforation or related complications; One patient with gastrointestinal involvement (intestinal edema) survived after ASCT.

\section{Statistical analyses results Comparison between refractory and non-refractory groups} Among 26 patients, 11 cases $(11 / 26,42.3 \%)$ were refractory and 15 were non-refractory. The differences of muscle strength, CMAS, SF and CD4/CD8 ratio between refractory and non-refractory group are shown in Fig. 1. There was no significant difference in BMI and CK between the two groups (Supplement 1). Furthermore, we analyzed the predictors of refractory JDM by univariate logistic regression (Table 3$)$. Edema $(P<0.0001)$, skin ulcers $(P=0.0003)$, severe muscle weakness (dysphagia/ hoarseness/soft voice, $P=0.0089$; muscle strength $<=$ grade $3, P=0.0041), \mathrm{CD} 4 / \mathrm{CD} 8$ ratio $<1.4(P=0.0255)$ and ferritin $>200 \mathrm{ng} / \mathrm{ml}(P=0.0361)$ were considerably associated with refractory JDM. ANA positive might be correlated with refractory JDM, but the difference was not significant $(P=0.0521)$. BMI and Ro-52 are not associated with refractory cases $(P>0.05)$. 

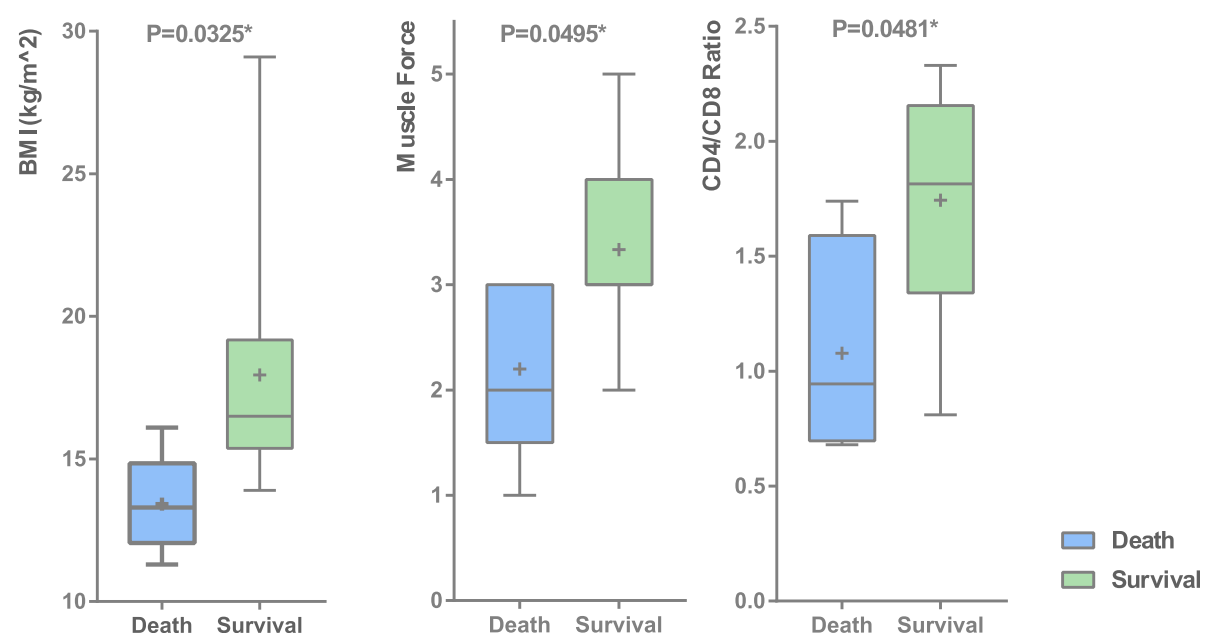

Fig. 1 The difference of $B M I$, muscle strength and CD4/CD8 ratio between survival and death

\section{Comparison between survival and death groups}

BMI $(P=0.0325)$, muscle strength $(P=0.0495)$ and CD4 / CD8 ratio $(P=0.0481)$ were significantly different between death and survival groups (Fig. 2). There was no significant difference in CMAS scores, CK and ferritin (Supplement 2). Univariate logistic regression analysis found that $\mathrm{BMI}<15(P=0.012)$ and ANA positive $(P=$ $0.0245)$ were highly correlated with mortality (Table 4$)$. Regarding the cause of death, 5 cases of children died of gastrointestinal involvement. The variables significantly associated with gastrointestinal involvement generally overlapped with the variables significantly associated with death. (Supplement 3).

As to treatment of JDM, during the follow up, 6 patients' CMAS were significantly increased. Nine severe cases including those with gastrointestinal involvement received biological agents treatment, such as rituximab and infliximab. JAKi was used in 7 cases because of no response to conventional therapy. All 7 cases showed good response on JAKi. A severe case, with skin ulcer, edema, muscle weakness and gastrointestinal involvement, received salvage treatment with ASCT. After ASCT, her situation was significantly improved; 2 years later, she went to kindergarten and no longer needed any medicine.

\section{Discussion}

JDM is a rare idiopathic inflammatory myopathy. Studies showed that more than 2 thirds of patients developed a chronic course and $4.1 \%$ of patients died [7, 8], patients have to taken drugs for years and some depends on wheelchair, which seriously affectsed patients' quality of life and social participation. MSA is potentially useful biomarker for it is associated with different clinical phenotypes $[9,10]$. In children with JDM, anti-MDA5, antiTIF-1 $\gamma$ and anti-NXP2 are the most common MSAs
[11-15]. The reports from UK and Argentina showed anti-NXP2 antibody were detected in 23 and 25\% respectively of patients with JDM $[16,17]$. In our study, anti-NXP2 seemed to be the most common antibody (30.6\%). The ratio of anti-NXP2 antibody in JDM was higher than that in western countries $[4,17,18]$, which may be because the severe patients from all over the country concentrated to our department. The present study reported the characteristics and high risk factors of poor response to the treatment and death of antiNXP2 antibody-related JDM in Chinese.

Twenty-six patients with anti-NXP2 antibody out of 85 JDM patients were involved. The female to male ratio was 1.9:1, which was different from reports of adult DM patients that anti-NXP2-antibodies were predominantly found in men $[19,20]$. The median age at onset is 4.5 years, which was younger than the average age of whole JDM cases [21].

As to the onset symptoms, muscle weakness and skin rash were the most common clinical manifestations of the JDM patients in this cohort (92.4\%). The skin lesions in this study included rashes (96.2\%), skin ulcer (38.5\%), edema (19.2\%) and calcification (11.5\%). Calcification was reported to be highly associated with the anti-NXP2 antibodies [5],while only $11.5 \%$ of patients showed calcification in our cohort, which might be related to active treatment due to the severe weakness [22]. In the cohort, $96.2 \%$ of patients manifested muscle weakness during the course of disease. Serious weakness (strength $<=$ grade 3) was found in $69.2 \%$ of patients. In the 15 patients with a CMAS $<10,9$ cases were found $\mathrm{CMAS}<=2$ and all manifested symptoms of palatal, laryngeal, and pharyngeal muscles group including dysphagia/hoarseness/soft voice. Magnetic resonance imaging (MRI) is preferred imaging modality for its noninvasive and no radiation. It is helpful in detecting sensitively monitor 
Table 3 Univariate logistic regression of refractory and non-refractory groups of anti-NXP2 autoantibody positive JDM

\begin{tabular}{|c|c|c|c|c|c|c|c|}
\hline & & Outcome ratio (\%) & $\mathbf{N}$ & $\beta$ & OR & $95 \% \mathrm{Cl}$ & $P$-values \\
\hline \multirow[t]{2}{*}{ Gender } & male & 33.33 & 26 & 0.5534 & 1.739 & $0.257 \sim 14.451$ & 0.8037 \\
\hline & female & 47.06 & & & & & \\
\hline \multirow[t]{2}{*}{$\mathrm{BMI}\left(\mathrm{kg} / \mathrm{m}^{2}\right)$} & $>=15$ & 33.33 & 25 & 1.5396 & 4.663 & $0.558 \sim 62.967$ & 0.2032 \\
\hline & $<15$ & 71.43 & & & & & \\
\hline \multirow[t]{2}{*}{ Muscle strength } & $>3$ & 0 & 26 & 2.6654 & 14.373 & $2.461 \sim>999.999$ & $0.0041^{*}$ \\
\hline & $<=3$ & 61.11 & & & & & \\
\hline \multirow[t]{2}{*}{ Edema } & No & 11.76 & 25 & 3.926 & 50.705 & $8.086 \sim>999.999$ & $<.0001^{*}$ \\
\hline & Yes & 100 & & & & & \\
\hline \multirow[t]{2}{*}{ Skin ulcer } & No & 12.5 & 26 & 3.8559 & 47.27 & 3.869 > 999.999 & $0.0003^{*}$ \\
\hline & Yes & 90 & & & & & \\
\hline \multirow[t]{2}{*}{ Dysphagia/hoarseness/soft voice } & No & 9.09 & 26 & 2.8634 & 17.521 & $1.691 \sim 952.094$ & $0.0089^{*}$ \\
\hline & Yes & 66.67 & & & & & \\
\hline \multirow[t]{2}{*}{ Symptom } & No & 10 & 26 & 2.5977 & 13.433 & $1.308 \sim 721.398$ & $0.0219^{*}$ \\
\hline & Yes & 62.5 & & & & & \\
\hline \multirow[t]{2}{*}{ ILD } & No & 27.78 & 25 & 1.7855 & 5.963 & $0.698 \sim 82.561$ & 0.1237 \\
\hline & Yes & 71.43 & & & & & \\
\hline \multirow[t]{2}{*}{ ANA (+) } & No & 21.43 & 26 & 1.9024 & 6.702 & $0.987 \sim 61.614$ & 0.0521 \\
\hline & Yes & 66.67 & & & & & \\
\hline \multirow[t]{2}{*}{ Anti-Ro-52 (+) } & No & 31.58 & 26 & 1.6178 & 5.042 & $0.609 \sim 67.675$ & 0.1696 \\
\hline & Yes & 71.43 & & & & & \\
\hline \multirow[t]{2}{*}{ CD4/CD8 ratio } & $>=1.4$ & 18.75 & 24 & 2.4221 & 11.269 & $1.26 \sim 171.48$ & $0.0255^{*}$ \\
\hline & $<1.4$ & 75 & & & & & \\
\hline \multirow[t]{2}{*}{ Ferritin (ng/ml) } & $<=200$ & 16.67 & 24 & 2.1876 & 8.914 & $1.115 \sim 123.379$ & $0.0361^{*}$ \\
\hline & $>200$ & 66.67 & & & & & \\
\hline
\end{tabular}

Outcome ratio the ratio of outcomes in different condition, Symptom at least one of edema, skin ulcer or Dysphagia/Hoarseness/Lower voice, BMI body mass index, ILD interstitial lung disease, ANA antinuclear antibody; *: significantly statistic difference, $P<0.05$

disease activity and muscle damage [23]. MRI showed muscle involvement in all 26 patients including those without muscle weakness. There was a girl, whose MRI revealed significant abnormalities but she had not muscle weakness at all, suggesting the importance of MRI in evaluating muscle involvement. Electromyography (EMG) showed myogenic damage in $69.2 \%$ of cases, suggesting it was not as sensitive as MRI [23].

The level of serum muscle enzymes plays an important role in the diagnosis of JDM. At the onset of the disease, 9.1\% cases were normal, $54.5 \%$ of cases varied from 1 to 10 times the normal levels and $36.4 \%$ of cases were higher than 10 times the normal levels. It was interesting that the CK level were almost normal in some patients who died of severe JDM; While in some cases who were sensitive to therapy or with mild symptoms, CK was significantly increased $(>10,000 \mathrm{U} / \mathrm{L})$. The phenomenon suggested that the level of CK was not associated with disease severity. As reported in the previous study, the markers that are currently used in clinical practice, AST, ALT, LDH, aldolase and in particular CK activity, do not correlate as well with disease activity in JDM as in DM [24]. Ueki $M$ found in their studies [11], that $50 \%$ of cases in the study were found with mildly elevated level of ALT, but whether it was liver dysfunction or not remains to be validated.

Previous assessment in America noted uncommon lung involvement in anti-NXP2 autoantibody JDM. A study of Caucasians reported that none of those cases with anti-NXP2 antibody JDM had any lung involvement $[3,25]$. However, in the study, HRCT revealed $26.9 \%$ of patients had mild ILD, while the corresponding pulmonary manifestations such as dyspnea and cough were not obvious. ILD quickly disappeared after treatment, which was not same as anti-MDA5 antibody-related JDM.

Of the 26 cases, 5 died of gastrointestinal perforation, which accounted for the vast majority of 6 deaths $(6 / 85)$, suggesting that anti-NXP2 antibody related complications accounted for majority of death in Chinese children with JDM. Among the death group, 4 of 5 patients were female. Statistical analysis showed significant differences of BMI, edema, skin ulcer, dysphagia/hoarseness/ 

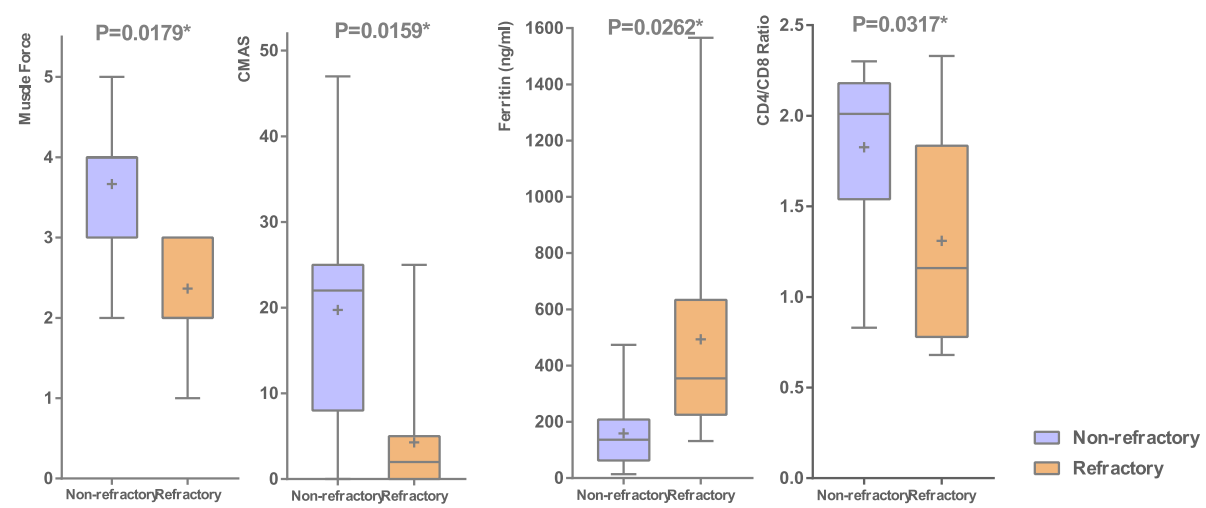

Fig. 2 The difference of muscle strength, CMAS, ferritin and CD4/CD8 ratio between refractory JDM and non-refractory JDM

soft voice, ANA (+) was found between death group and survival group as well as in groups with and without gastrointestinal involvement.

Among the 5 deaths, very low BMI $(<13)$ could be seen in 4 children. Univariate logistic regression analysis found BMI $<15(P=0.012)$ was highly correlated with death. The very low BMI might be a result of chronic gastrointestinal before perforation [26]. There are limitations of the study: Firstly, our center is a large referral center and likely to receive more severe and more refractory cases which may lead to a biased population. Secondly, the present study is a retrospective approach and based on only 1 medical center. What's more, the length of follow-up for assessment of death is limited and lack of function status assessment and disease course (monocyclic, polycyclic, remission). Multicenter

Table 4 Univariate logistic regression of survival and death groups of anti-NXP2 autoantibody positive JDM

\begin{tabular}{|c|c|c|c|c|c|c|c|}
\hline & & Outcome ratio (\%) & $\mathbf{N}$ & B & OR & $95 \% \mathrm{Cl}$ & $P$ value \\
\hline \multirow[t]{2}{*}{ Gender } & Male & 11.11 & 26 & 0.8695 & 2.386 & $0.188 \sim 136.137$ & 0.8394 \\
\hline & Female & 23.53 & & & & & \\
\hline \multirow[t]{2}{*}{$\mathrm{BMI}(\mathrm{kg} / \mathrm{m} 2)$} & $>=15$ & 5.56 & 25 & 2.9305 & 18.737 & $1.328 \sim>999.999$ & $0.0245^{*}$ \\
\hline & $<15$ & 50 & & & & & \\
\hline \multirow[t]{2}{*}{ Muscle strength } & $>3$ & 0 & 26 & 1.2982 & 3.663 & $0.585 \sim>999.999$ & 0.1303 \\
\hline & $<=3$ & 27.78 & & & & & \\
\hline \multirow[t]{2}{*}{ Edema } & No & 0 & 25 & 2.8369 & 17.062 & $2.562 \sim>999.999$ & $0.0055^{*}$ \\
\hline & Yes & 50 & & & & & \\
\hline \multirow[t]{2}{*}{ Skin ulcer } & No & 0 & 26 & 2.8358 & 17.045 & 2.722 > 999.999 & $0.0038^{*}$ \\
\hline & Yes & 50 & & & & & \\
\hline \multirow[t]{2}{*}{ dysphagia/hoarseness/soft Voice } & No & 0 & 26 & 1.8624 & 6.439 & $1.044 \sim>999.999$ & $0.0457^{*}$ \\
\hline & Yes & 33.33 & & & & & \\
\hline \multirow[t]{2}{*}{ Symptom } & No & 0 & 26 & 1.6794 & 5.362 & $0.867 \sim>999.999$ & 0.0664 \\
\hline & Yes & 31.25 & & & & & \\
\hline \multirow[t]{2}{*}{ ILD } & No & 5.56 & 25 & 2.4074 & 11.105 & $0.696 \sim 707.076$ & 0.1051 \\
\hline & Yes & 42.86 & & & & & \\
\hline \multirow[t]{2}{*}{ ANA (+) } & No & 0 & 26 & 2.4202 & 11.248 & $1.819 \sim>999.999$ & $0.012^{*}$ \\
\hline & Yes & 41.67 & & & & & \\
\hline \multirow[t]{2}{*}{ Anti-Ro-52 (+) } & No & 15.79 & 26 & 0.7253 & 2.065 & $0.136 \sim 24.28$ & 0.8215 \\
\hline & Yes & 28.57 & & & & & \\
\hline \multirow[t]{2}{*}{ CD4/CD8 ratio } & $>=1.4$ & 6.25 & 24 & 2.0877 & 8.066 & $0.517 \sim 502.932$ & 0.1818 \\
\hline & $<1.4$ & 37.5 & & & & & \\
\hline
\end{tabular}


and large sample study needs to be carried out to verify the findings.

\section{Conclusions}

We observed that patients presenting with edema, skin ulcer and dysphagia/hoarseness/soft voice are more associated with requiring more aggressive therapy and more associated with mortality. Decreased CD4/CD8 ratio and high ferritin are associated with refractory cases. Further more, Low BMI and positive ANA were associated with gastrointestinal involvement and mortality. Further prospective multicenter study is needed to verify these findings.

\section{Supplementary Information}

The online version contains supplementary material available at https://doi. org/10.1186/s12969-020-00492-z.

Additional file 1: Supplement 1. Characteristics of Refractory and Nonrefractory.

Additional file 2: Supplement 2. Characteristics of Death and Survival and Anti-NXP2 antibody-positive JDM With and Without Gastrointestinal Involvement.

Additional file 3: Supplement 3. univariate logistic regression results in anti-NXP2 antibody-positive JDM with and without gastrointestinal involvement.

\section{Abbreviations}

NXP2: Nuclear matrix protein 2; TIF-1 $\gamma$ : Transcriptional intermediary factor $1 \gamma_{i}$ MDA5: Me lanoma differentiation associated gene; JDM: Juvenile dermatomyositis; JPM: Juvenile polymyositis; IIM: Idiopathic inflammatory myopathies; MSA: Myositis-specific autoantibody; ASCT: Autologous stem cell transplant; JAKi: Janus kinase inhibitor; IVIG: Intravenous immunoglobulin; BMI: Body mass index; ANA: Anti-nuclear antibody; HRCT: High-resolution computed tomography; IVIG: Intravenous immunoglobulin; MRI: Magnetic resonance imaging; ILD: Interstitial lung disease; EMG: Electromyography; CMAS: Childhood myositis assessment score; CK: Creatine kinase

\section{Acknowledgements}

Not applicable.

\section{Authors' contributions}

Dr. Jianguo Li and Zhixuan Zhou substantially contributed to study design, analysis and interpretation of data and revised the article for important intellectual content. Dr. Xinning Wang and Yuchuan Ding analyzed and interpreted the patient data and were major contributor in writing the manuscript. Dr. Jun Hou and Yingjie Xu contributed to acquisition, analysis and interpretation of data and revise the article critically. All authors were involved in drafting the article or revising it critically for important intellectual content, and all authors approved the final version to be published

\section{Funding}

This study was funded by Beijing Municipal Administration of Hospitals Clinical medicine Development of special funding support, grant number: XMLX201813.

\section{Availability of data and materials}

All data generated or analyzed during this study are included in this published article and its supplementary information files.

\section{Ethics approval and consent to participate}

This study was approved by Ethics Committee of CIP (KSSHERLL2017068).

\section{Consent for publication}

Not applicable.

\section{Competing interests}

The authors declare that they have no competing interests.

Received: 6 June 2020 Accepted: 9 December 2020

Published online: 06 January 2021

\section{References}

1. Whitaker JN, Engel WK. Vascular deposits of immunoglobulin and complement in idiopathic inflammatory myopathy. N Engl J Med. 1972;286: 333-8.

2. Meyer A, Meyer N, Schaeffer M, Gottenberg JE, Geny B, Sibilia J. Incidence and prevalence of inflammatory myopathies: a systematic review. Rheumatology. 2015:54:50-63. https://doi.org/10.1093/rheumatology/keu289.

3. Rider LG, Shah M, Mamyrova G, Huber AM, Rice MM, Targoff IN, et al. The myositis autoantibody phenotypes of the juvenile idiopathic inflammatory myopathies. Medicine (Baltimore). 2013;92(4):223-43. https://doi.org/10. 1097/MD.0b013e31829d08f9.

4. Espada G, Maldonado Cocco JA, Fertig N, Oddis CV. Clinical and serologic characterization of an argentine pediatric myositis cohort: identification of a novel autoantibody (anti-MJ) to a 142-kDa protein. J Rheumatol. 2009; 36(11):2547-51. https://doi.org/10.3899/jrheum.090461.

5. Tansley SL, Betteridge ZE, Shaddick G, Gunawardena H, Arnold K, Wedderburn $L R$, et al. Calcinosis in juvenile dermatomyositis is influenced by both antiNXP2 autoantibody status and age at disease onset. Rheumatology. 2014; 53(12):2204-8. https://doi.org/10.1093/rheumatology/keu259.

6. Rider LG, Shah M, Mamyrova G, et al. The myositis autoantibody phenotypes of the juvenile idiopathic inflammatory myopathies. Medicine (Baltimore). 2013;92:223-43.

7. Ravelli A, Trail L, Ferrari C, Ruperto N, Pistorio A, Pikington C, et al. Longterm outcome and prognostic factors of juvenile dermatomyositis: a multinational, multicenter study of 490 patients. Arthritis Care Res. 2010; 62(1):63-72. https://doi.org/10.1002/acr.20015.

8. Mathiesen P, Hegaard H, Herlin T, Zak M, Pedersen FK, Nielsen. Long-term outcome in patients with juvenile dermatomyositis: a crosssectional follow-up study. Scand J Rheumatol. 2012:41:508. https://doi.org/10.3109/03009742.2011.608376.

9. Holton JL, Wedderburn LR, Hanna MG. Polymyositis, dermatomyositis, and inclusion body myositis [M]// muscle disease: pathology and genetics. 2nd ed; 2013. https://doi.org/10.1002/9781118635469.ch33.

10. Ramanan AV, Feldman BM. Clinical features and outcomes of juvenile dermatomyositis and other childhood onset myositis syndromes. Rheuma Dis Clin North Am. 2002;28(4):833-57. https:/doi.org/10.1016/s0889-857x(02)00024-8.

11. Ueki M, Kobayashi I, Takezaki S, Tozawa Y, Okura Y, Yamada M, et al. Myositis-specific autoantibodies in Japanese patients with juvenile idiopathic inflammatory myopathies. Mod Rheumatol. 2019;29(2):351-6. https://doi.org/10.1080/14397595.2018.1452353.

12. Betteridge Z, McHugh N. Myositis-specific autoantibodies: an important tool to support diagnosis of myositis. J Intern Med. 2016;280(1):8-23. https://doi. org/10.1111/joim.12451.

13. Bodoki L, Nagy-Vincze M, Griger Z, Betteridge Z, Szöllősi L, Dankó K, et al. Four dermatomyositis-specific autoantibodies-anti-TIF1 $\gamma$, anti-NXP2, antiSAE and anti-MDA5 - in adult and juvenile patients with idiopathic inflammatory myopathies in a Hungarian cohort. Autoimmun Rev. 2014; 13(12):1211-9. https://doi.org/10.1016/j.autrev.2014.08.011.

14. Fiorentino DF, Kuo K, Chung L, Zaba L, Li S, Casciola-Rosen L, et al. Distinctive cutaneous and systemic features associated with antitranscriptional intermediary factor- $1 \gamma$ antibodies in adults with dermatomyositis. J Am Acad Dermatol. 2015;72(3):449-55. https://doi.org/10. 1016/j.jaad.2014.12.009.

15. Fujimoto $M$, Hamaguchi $Y$, Kaji $K$, Matsushita $T$, Ichimura $Y$, Kodera $M$, et al. Myositis-specific anti-155/140 autoantibodies target transcription intermediary factor 1 family proteins. Arthritis Rheum. 2012;64(2):513-22. https://doi.org/10.1002/art.33403.

16. Gunawardena H, Wedderburn LR, Chinoy H, Betteridge ZE, North J, Ollier $W E$, et al. Autoantibodies to a 140-kd protein in juvenile dermatomyositis are associated with calcinosis. Arthritis Rheumatol. 2009:60(6):1807-14. https://doi.org/10.1002/art.24547.

17. Ceribelli A, Fredi M, Taraborelli M, Cavazzana I, Franceschini F, Quinzanini M, et al. Anti-MJ/NXP-2 autoantibody specificity in a cohort of adult Italian patients with polymyositis/dermatomyositis. Arthritis Res Ther. 2012;14(2): R97. https://doi.org/10.1186/ar3822. 
18. Bohan A, Peter JB. Polymyositis and dermatomyositis (second of two parts). N Engl J Med. 1975;292(8):403-7. https://doi.org/10.1056/ NEJM197502202920807.

19. Ichimura $Y$, Matsushita T, Hamaguchi $Y$, Kaji K, Hasegawa M, Tanino Y, et al. Anti-NXP2 autoantibodies in adult patients with idiopathic inflammatory myopathies: possible association with malignancy. Ann Rheum Dis. 2012; 71(5):710-3. https://doi.org/10.1136/annrheumdis-2011-200697.

20. Merlo G, Clapasson A, Cozzani E, Sanna L, Pesce G, Bagnasco M, et al. Specific autoantibodies in dermatomyositis: a helpful tool to classify different clinical subsets. Arch Dermatol Res. 2017;309(2):87-95. https://doi. org/10.1007/s00403-016-1704-1.

21. Martin N, Krol P, Smith S, Murray K, Pilkington CA, Davidson JE, et al. A national registry for juvenile dermatomyositis and other paediatric idiopathic inflammatory myopathies: 10 years' experience; the Juvenile Dermatomyositis National (UK and Ireland) cohort biomarker study and repository for idiopathic inflammatory myopathies. Rheumatology. 2011;50: 137-45. https://doi.org/10.1093/rheumatology/keq261.

22. Li J, Zhou Z. Calcinosis in juvenile dermatomyositis. N Engl I Med. 2019; 381(16):e31. https://doi.org/10.1056/NEJMicm1809669.

23. Rider LG, Aggarwal R, Machado MP, Hogrel J-Y, Reed AM, Christopher-Stine $L$, et al. Update on outcome assessment in myositis. Nat Rev Rheumatol. 2018;14(5):303-18. https://doi.org/10.1038/nrrheum.2018.33.

24. Wienke J, Deakin CT, Wedderburn LR, Wijk F, Royen-Kerkhof A. Systemic and tissue inflammation in juvenile dermatomyositis: from pathogenesis to the quest for monitoring tools. Front Immunol. 2018;9:2951.

25. Ceribelli A, Fredi M, Taraborelli M, Cavazzana I, Franco F, Tincani A, et al. AntiMJ/NXP-2 antibodies are the most common specifcity in a cohort of adult caucasian patients with dermatomyositis. Ann Rheum Dis. 2012;71(Suppl 1): A49.2-A49. https://doi.org/10.1136/annrheumdis-2011-201235.17.

26. Papadopoulou C, McCann $\amalg$. The vasculopathy of juvenile dermatomyositis. Front Pediatr. 2018;6:284. https://doi.org/10.3389/fped.2018.00284.

\section{Publisher's Note}

Springer Nature remains neutral with regard to jurisdictional claims in published maps and institutional affiliations.

Ready to submit your research? Choose BMC and benefit from:

- fast, convenient online submission

- thorough peer review by experienced researchers in your field

- rapid publication on acceptance

- support for research data, including large and complex data types

- gold Open Access which fosters wider collaboration and increased citations

- maximum visibility for your research: over $100 \mathrm{M}$ website views per year

At $\mathrm{BMC}$, research is always in progress.

Learn more biomedcentral.com/submissions 